\title{
British nuclear workforce assessed for risks
}

RFsulis of a study carried out by the British Medical Research Council (MRC) claim that there is "no significant risk to health" from radiation to people working for the UK Atomic Energy Authority (AEA). The study, published last week in the British Medical Journal (291, 435 and $440 ; 1985)$, relates mortality to recorded exposure to ionizing radiation for 39,546 employees of AEA between 1946 and 1979. Of the 3,373 deaths that occurred, 937 were from cancers; overall, death rates of the sample population were lower than those in the country as a whole, but consistent with those expected in a normal workforce and probably accounted for by the social class of AEA employees. But one type of cancer, prostate cancer, was unusually prevalent in the sample group.

The UK study was undertaken as a re sult of a report in 1977 from the United States, which suggested that the risk of developing cancer after exposure to lowdose ionizing radiation is 20 times greater than the recommendations of the International Commission on Radiological Protection (ICRP). That study, which investigated a workforce in the US nuclear industry, has been criticized for its methodology and analysis of results. AEA therefore asked MRC to commission an independent survey of mortality in its own workforce. MRC's epidemiological study was performed by Professor Geoffrey Rose, Dr Valerie Beral and colleagues at the London School of Hygiene and Tropical Medicine. Mortality of all AEA employees since 1946 was examined and the results compared with ICRP's figures.

The authors of the new study say that their data give no unambiguous guide to the feasibility of estimating the radiation risks to people exposed to low doses by extrapolation from the mortality among the survivors of atomic bomb explosions, exposed to acute doses, the basis of the ICRP recommendations. The correlation between radiation exposure and mortality is so uncertain that, at the 9.5 per cent confidence limits, the data are consistent with a chronic radiation risk 15 times greater than that suggested by ICRP and, at the other extreme, a risk which decreases with increasing dose.

Of the deaths that occurred, leukaemia rates were slightly above the national average, but as the total number of deaths from this cause was small (35 overall, or 4 per cent of all cancer deaths) the excess could be explained by chance fluctuations. Mortality was not, in general, correlated with radiation exposure, the exception being prostate cancer, which caused 38 deaths. This figure is several times greater than the national average in the small groups of workers who had relatively high exposure to radiation and who had also been monitored for contamination by radionuclides, particularly tritium. No explanation for this result is suggested by the British Medical Journal papers, which point out that tritium is not prostateseeking, but that tritium contamination may be an indicator of some other agent.

MRC is now "actively considering" how to investigate further the results on prostatic cancer. The epidemiological study is being extended for a further five years, partly to obtain more reliable statistics and partly because, as pcople in the sample become older, more cancers will emerge which will allow risk estimates to be recalculated with greater precision.

Over the next fow years, other UK studies on the effects of radiation will attain the stage that this MRC/AEA survey has reached. Studies in progress are on atomic weapons research staff, staff of British Nuclear Fuels Ltd (preliminary results already published), the National Radiological Protection Board's radiation register for the 1970s and the Central Electricity Generating Board's survey on its workforce. Pooling of these results with the existing and future AEA figures from surveys in other countries will enable more confident limits to be set on radiation safety levels and provide a more accurate estimate of the specific risks involved.

Maxine Clarke

\section{Japanese economy}

\section{The future is even brighter}

\section{Tokyo}

JAPAN's economic prospects will be even brighter in the years ahead. That is the message of the latest white paper from the Economic Planning Agency. And although the document repeats the familiar self-criticism of recent years that Japan lags behind the United States and Europe in fundamental science and the development of original technology, the criticism is only muted.

Indeed, the report predicts an economic future for which most European leaders would sell their souls. The past ten years - in which annual growth has regularly been above 5 per cent, two or three times that recorded in the United Kingdom, and in which Japan has emerged as the world's second greatest economic power - is dismissed as an era of "stagflation". From now on, Japan will enter a new age of inflation-free rapid growth.

Three factors will contribute to this expansion. The first is rapid growth in the telecommunications, electronics and other high-technology industries. In 1984 alone, Japanese corporations invested five thousand million yen $\left(10^{12}\right)$ in these areas. Second is the growing service sector and increasing urbanization, with the Japanese population becoming ever more concentrated. And third is the growth of Japan's Pacific neighbours - from California through Australia round to Taiwan, Korea and China - which, it is believed. will make the Pacific basin the centre of world economic activity by the turn of the century, leaving the Atlantic nations to wither in their grey and sunless climes.

Only one small cloud floats in this perfect blue sky. Japan now supports a smaller percentage of old people than European countries. But by the end of the century, with the Japanese now the world's longest lived people, the situation will have reversed and the nation will be faced by huge pension and medical bills. The report suggests that this may be dealt with by raising from 60 to 65 the age at which citizens can receive government pensions and by restricting the number of doctors. And that in turn has led to stern criticism that economic planning agencies have no business deciding welfare policy.

Alun Anderson

$\overline{\text { More money for NIH }}$

\section{Washington}

In the last days before its summer break, the US Congress defied the administration by passing a bill instructing the National Institutes of Health (NIH) to award no less than 6,200 extramural research grants in the current fiscal year, slightly less that Congress originally intended but 1,200 more than the administration's planned figure of 5,000 grants.

Thwarted by Congress's limitless generosity to NIH, the administration had tried to commit some of the $\mathbf{1 9 8 5}$ budget for the future years of multi-year grants, a move that was challenged on legal grounds by the US Comptroller General. The supplemental appropriation now passed by Congress (HR2577) does not give NIH any money above the $\$ 938$ million they had already been given for research grants, but by specifying the number of grants, it prevented the administration from pursuing the multi-year funding plan (see Nature 313,$377 ; \mathbf{1 9 8 5}$ ). The legality of the administration's plan has not been resolved.

Researchers should not expect their money too soon, however. By denying his signature, President Reagan could yet exercise a "pocket veto" and kill the bill, as Congress is not in session to oppose him.

Tim Beardsley 